\title{
A homogeneização do ensino secundário na década de 1930: estratégias de eficiência, racionalidade e controle
}

\section{The Homogenization of Secondary Education in the decade of 1930: strategies for efficiency, rationality and control}

\author{
Geysa Spitz Alcoforado de Abreu ${ }^{1}$
}

\begin{abstract}
RESUMO
O objetivo deste texto é discutir algumas medidas que evidenciam a crescente atenção por parte da administração brasileira quanto às instalações dos estabelecimentos destinados ao ensino secundário, a partir do decreto-lei $\mathrm{n}^{\circ} 19.890$ - de 18 de abril de 1931. Para tanto, parte-se da análise do documento intitulado "Classificação dos Estabelecimentos de Ensino Secundário”, do Ministério da Educação e Saúde, consubstanciada na portaria de 15 de abril de 1932, elaborado por Anísio Teixeira, Paulo de Assis Ribeiro, Otavio Martins, dentre outros, que foram buscar nos standards de Strayer e Engelhardt as normas que julgavam necessárias adotar e adaptar para o Brasil; bem como suas repercussões num estabelecimento de ensino secundário, fundado em Curitiba, em 1935, a saber, o Ginásio Belmiro César, utilizando como fontes a legislação sobre o ensino secundário e relatórios de inspeção federal. A legislação que entrou em vigor, nos anos de 1930, visava à homogeneização do ensino secundário em instituições públicas e privadas, em todo o território nacional. Dentre as medidas complementares adotadas, merece especial atenção a implantação de uma sistemática de inspeção, por meio da qual poderiam ser alcançados níveis mais altos de eficiência, racionalidade e controle. Ainda que documentos oficiais e estudos em torno da matéria destaquem as grandes dificuldades enfrentadas pelo governo federal de fazer funcionar a sistemática de inspeção instituída, a sua força disciplinadora e de controle dos inspetores federais pode ser aferida, no caso do Ginásio Belmiro César.

Palavras-chave: Ensino Secundário; Inspeção Pública; Paraná.
\end{abstract}

1 Professora Doutora da Universidade do Estado de Santa Catarina (UDESC), Brasil. E-mail: geysa.abreu@uol.com.br. 


\begin{abstract}
The purpose of this paper is to discuss some measures that highlight the growing attention from the Brazilian government towards the institutions for secondary education following the executive order 19.890, of April 18, 1931. Thus, it starts from the analysis of the document entitled "Classification of Secondary Education Establishments", of the Ministry of Education and Health, embodied in the regulation of April 15, 1932, which was prepared by Anísio Teixeira, Paulo de Assis Ribeiro, Otavio Martins, among others who examined the standards of Strayer and Engelhardt searching for norms deemed necessary to adopt and adapt to Brazil; as well as its repercussions in a secondary education establishment founded in Curitiba, in 1935, namely the Ginásio Belmiro César, using the legislation about the secondary education and federal inspection reports as sources. The legislation that came into force in the 1930's aimed to homogenize secondary education in public and private institutions, throughout the national territory. Among the supplementary measures adopted, special attention is deserved to the implementation of a systematic of inspection, through which higher levels of efficiency, rationality and control could be achieved. Although official documents and studies regarding the subject emphasize the vast difficulties faced by the federal government to operate the systematic of inspection instituted, its disciplinary force and the control of the federal inspectors can be verified, in the case of the Ginásio Belmiro César.
\end{abstract}

Keywords: Secondary Education; Public Inspection; Paraná.

\title{
Introdução
}

O objetivo deste texto é discutir algumas medidas que evidenciam a crescente atenção por parte da administração brasileira quanto às instalações dos estabelecimentos destinados ao ensino secundário, a partir do decreto-lei $\mathrm{n}^{\mathrm{o}} 19.890$ - de 18 de abril de 1931, posteriormente conhecido como Reforma Francisco Campos. Para tanto, foram utilizadas como fontes a legislação sobre o ensino secundário e relatórios de inspeção federal relativos ao Ginásio Belmiro César, localizados no acervo do colégio, em Curitiba. ${ }^{2}$

O Ginásio Belmiro César é um prolongamento da Escola Americana de Curitiba, vendida para um Reverendo da Igreja Presbiteriana, em 1934.

Em 1935, o Rev. Luiz Lens de Araújo César, novo proprietário, inaugurou o Ginásio Belmiro César, que funcionaria com o curso ginasial, paralelamente

2 Trata-se de um acervo privado, conservado pela família do ex-proprietário da Escola. 
ao ensino primário ofertado pela Escola Americana de Curitiba ${ }^{3}$. Tal instituição tornou-se um estabelecimento de grande expressão na cidade, tendo formado gerações de pessoas de grande representatividade na sociedade paranaense.

Não será objeto deste texto adentrar pelas medidas e ensaios de reformas efetuados desde o período Imperial até o governo provisório, nem mesmo nas medidas que já haviam sido tentadas pelo Decreto n. ${ }^{\circ} 16.782$-A, de 13 de janeiro de $1925^{4}$ e que são reiteradas pela legislação de 1931, a partir da qual o ensino secundário adquire uma configuração curricular e perfil forte de um tipo e grau de ensino.

\section{A conformação do Ensino Secundário: o Decreto- lei no 19.890 - de 18 de abril de 1931}

Em 1930, o Governo Provisório criou o Ministério da Educação e Saúde Pública, para o qual Francisco Campos foi nomeado ministro. Dentre as primeiras medidas tomadas, Campos baixou uma série de decretos-lei que alteravam ou constituíam graus e modalidades de ensino ${ }^{5}$.

Quanto ao ensino secundário, o decreto-lei $\mathrm{n}^{\circ} 19.890$ - de 18 de abril de 1931 conferiu um grau maior de organicidade a esse nível de ensino, ao estabelecer o currículo seriado, a frequência obrigatória e a exigência de diploma de nível secundário para o ingresso no ensino superior, medida já presente na reforma de 1925, mas ainda não implementada ${ }^{6}$. Pelo mesmo decreto, o ensino

3 Em 1945, o Colégio Belmiro César passou a oferecer também o curso colegial e em 1956 encerrou definitivamente suas atividades.

4 Posteriormente conhecido como Reforma Francisco Alves / Rocha Vaz. Essa pode ser considerada a primeira iniciativa de caráter mais abrangente, estabelecendo o "ensino secundário, como prolongamento de ensino primário, para fornecer a cultura média geral do país", compreendendo um curso de estudos com a duração de seis anos (art. 47); a supressão dos exames parcelados de preparatórios e a exigência do certificado de aprovação final no $5^{\circ}$ ano do curso secundário como condição indispensável para a admissão a exame vestibular para a matrícula em qualquer curso superior (art. 54). Contudo, naquele mesmo ano, iniciou-se um combate à reforma e, sob forte pressão, o governo federal recuou, promovendo alterações que representaram um retorno ao regime anterior.

5 Decreto $\mathrm{n}^{\circ} 19.850$ - de 11 de abril de 1931: Cria o Conselho Nacional de Educação; Decreto $\mathrm{n}^{\circ} 19.851$ - de 11 de abril de 1931: Dispõe sobre a organização do ensino superior no Brasil e adota o regime universitário; Decreto $\mathrm{n}^{\circ} 19.852$ - de 11 de abril de 1931: Dispõe sobre a organização da Universidade do Rio de Janeiro; Decreto $\mathrm{n}^{\circ} 19.890$ - de 18 de abril de 1931: Dispõe sobre a organização do ensino secundário; Decreto $n^{\circ} 20.158$ - de 30 de junho de 1931: Organiza o ensino comercial, regulamenta a profissão de contador e dá outras providências; Decreto $\mathrm{n}^{\circ} 21.241-\mathrm{de}$ 14 de abril de 1932: Consolida as disposições sobre o ensino secundário.

6 Ver: Decreto 5.303-A, de 31 de outubro de 1927; Decreto 5.578, de 16 de novembro de 1928. 
secundário foi subdivido em dois ciclos: um fundamental, de cinco anos de duração, e outro complementar, de dois anos ${ }^{7}$.

A determinação do mesmo currículo, dos mesmos programas, bem como de métodos, critérios de avaliação e sistema de provas indica que estava em jogo a homogeneização do ensino secundário tanto no que se refere às escolas públicas e privadas, como na sua extensão nacional. Por decorrência, foram adotadas medidas complementares que pressionaram as escolas a adotar padrões de administração racionalizados e burocratizados, ou seja, a adaptação a um conjunto de normas baseadas em pressupostos científicos sobre como a escola deveria ser organizada.

Dentre as medidas complementares adotadas, merece especial atenção a implantação de uma sistemática de inspeção, por meio da qual poderiam ser alcançados níveis mais altos de eficiência, racionalidade e controle.

Ainda que documentos oficiais e estudos em torno da matéria destaquem as grandes dificuldades enfrentadas pelo governo federal de fazer funcionar a sistemática de inspeção instituída, a sua força disciplinadora e de controle dos inspetores federais pode ser aferida no caso do Ginásio Belmiro César.

A força disciplinadora da Reforma Francisco Campos se evidencia, por exemplo, pelas exigências relativas às instalações dos estabelecimentos de ensino secundário para fins do "reconhecimento oficial". O ensino secundário "oficialmente reconhecido" seria apenas o ministrado no Colégio Pedro II e em estabelecimentos sob regime de inspeção oficial (cf. art. $1^{\circ}$ do Decreto n. 21.241, de 14/4/1932). Somente os exames desses colégios seriam reconhecidos pelo governo federal e dariam aos alunos diplomados o direito à matrícula nos cursos pré-universitários, nas Faculdades oficiais ou equiparadas. Somente alunos de estabelecimentos oficialmente inspecionados teriam o direito à transferência para outros estabelecimentos de ensino secundário oficiais, equiparados ou sob inspeção preliminar.

Ao se prever cuidadosamente as instalações adequadas ao estudo e ao recreio dos alunos, a aeração e a iluminação das salas de aula, além dos "meios auxiliares à boa prática docente", tais como: laboratórios, salas especiais e equipamentos minuciosamente discriminados, evidencia-se a tentativa de superação de um tempo em que os estabelecimentos de ensino secundário se contentavam em adaptar, "mais ou menos convenientemente, prédios residenciais às suas necessidades" (BRASIL, [193?], p. 3).

7 O primeiro ciclo, de formação básica geral, tornou-se obrigatório para o ingresso no ensino superior. O segundo ciclo foi estruturado como curso propedêutico, possuía um currículo diferenciado para preparar candidatos à Faculdade de Direito; às Faculdades de Medicina, Odontologia e Farmácia; e aos cursos de Engenharia e Arquitetura. 
O documento intitulado "Classificação dos Estabelecimentos de Ensino Secundário", do Ministério da Educação e Saúde, consubstanciada na portaria de 15 de abril de 1932, é expressão da preocupação por parte da administração brasileira quanto às instalações dos estabelecimentos destinados a esse nível de ensino. O referido documento foi elaborado por Anísio Teixeira, Paulo de Assis Ribeiro, Otávio Martins ${ }^{8}$, dentre outros, que foram buscar nos standards de Strayer e Engelhardt ${ }^{9}$ as normas que julgavam necessárias adotar e adaptar para o Brasil.

\section{Um novo e grande Instituto secundário: O Ginásio Belmiro César}

Conforme determinava o artigo 51 do decreto $\mathrm{n}^{\circ} 21.241$, de 14 de abril de 1932, os estabelecimentos de ensino que pretendessem solicitar o reconhecimento oficial deveriam "Dispor de edifício, instalações e material didático, de acordo com as normas estabelecidas pelo Departamento Nacional do Ensino e aprovadas pelo Ministro da Educação e Saúde Pública”.

Ao adquirir a Escola Americana, em fins de 1934, o Rev. Luiz Lenz de Araújo César, viajou para os Estados Unidos, onde permaneceu por cinco meses em visitas a escolas e universidades. Durante a viagem, adquiriu equipamentos e material didático, para o novo ginásio que iria fundar. A ordenação dos espaços de acordo com seus usos e suas funções assumia um papel mais importante nas instituições educativas.

Ao retornar de sua viagem, o Reverendo César tratou de adequar o estabelecimento às exigências impostas pela Reforma Francisco Campos, pois os estabelecimentos de ensino que pretendessem solicitar o reconhecimento oficial deveriam atender as normas prescritas no artigo 51 do Decreto $n^{\circ} 21.241$, a saber:

I - Dispor de edifício, instalações e material didático, de acordo com as normas estabelecidas pelo Departamento Nacional do Ensino e aprovadas pelo Ministro da Educação e Saúde Pública; II - Ter corpo docente inscrito no registro de professores; III - Manter na sua direção, em exercício efetivo, pessoa de notória competência e irrepreensível conduta moral;

8 Otávio Martins era engenheiro, com estudos especializados em educação; e Paulo de Assis Ribeiro, arquiteto.

9 George D. Strayer e N.C. Engelhardt eram pesquisadores do Teacher's College da Universidade de Colúmbia. Ver: STRAYER, George D.; ENGELHARDT, N. L. Standards for Elementary School buildings. New York: Bureau of Publications, Teacher's College, Columbia University, 1933. 
IV - Oferecer garantias financeiras bastantes para o funcionamento durante o período mínimo de dois anos;

$\mathrm{V}$ - Obedecer à organização didática e o regime escolar estabelecidos neste decreto.

Em janeiro de 1935, o Ginásio Belmiro César já devidamente instalado, estava apto a ser avaliado para solicitar a autorização de funcionamento ${ }^{10}$. Assim noticiava o jornal "O Dia" de 10 de janeiro de 1935:

Vae se abrir nesta capital um dos maiores gymnasios do sul do Brasil.

[...]O novo instituto funccionará nos colossaes prédios onde até há pouco se achava installada a Escola Americana e que occupam um terreno que dá frente para a rua Commendador Araújo e fundos para a Avenida Vicente Machado.[...] O collegio comprehende três prédios: o de aulas, o internato e a residência do director. No primeiro, há nada menos de 15 amplas salas de aula, todas com illuminação directa e com capacidade para mais de 50 alumnos. Além disso, há salas de audição, de concertos, e archivo, portaria, direcção, etc. Todas as salas estão dotadas de material de primeira ordem, desde as carteiras ao material pedagógico. Este procedeu do estrangeiro e do Brasil e foi rigorosamente escolhido para attender a sua finalidade. Os museus de história natural, physica e chimica são completos e são a ultima palavra no assumto. Há salas especiais de historia natural, geographia, historia da civilização, etc. As salas de physica e chímica são com material para manipulação individual. O dormitório é constituído de quartos amplos com capacidade para três alumnos bem accommodados. Há salas de estudos, de sociabilidade, enfermaria, etc. Tudo está muito bem installado, sendo certo que a nova casa de ensino será uma das maiores e mais bem apparelhadas do sul do Brasil, honrando, portanto, os foros de progresso de nosso Estado... (Jornal "O Dia”, de 10/01/35).

No texto do jornal, percebe-se a ênfase nas instalações físicas e materiais como representativas do progresso do Estado do Paraná.

Antes da inauguração do Ginásio Belmiro César, o Rev. Luiz L. César entrou com um pedido de verificação prévia para a concessão de reconhecimento sob regime de inspeção preliminar, junto ao Ministério da Educação e Saúde.

10 Na ocasião, Curitiba tinha uma população de cerca de 120.000 habitantes, e existiam nove estabelecimentos de ensino fiscalizados na cidade. 
Conforme determinava o artigo 52 do Decreto $\mathrm{n}^{\circ} 21.241$, os estabelecimentos de ensino secundário que atendessem às exigências legais, seriam submetidos a um regime de inspeção preliminar por um período mínimo de dois anos. Após o período de inspeção preliminar, caso o estabelecimento fosse considerado aprovado por uma comissão de inspetores, seria concedida a inspeção permanente por decreto do Governo Federal (art. 55), tornando-se equiparado ao Colégio Pedro II e designado estabelecimento livre de ensino secundário.

No início de 1935, por ordem do Dr. Nóbrega da Cunha, Inspetor Geral do Ensino Secundário (Rio de Janeiro), foi realizada a verificação do Ginásio Belmiro César, pelo Inspetor Federal Sr. Armando Petrelli, do "Colégio Iguassú"

Para a realização da avaliação das condições dos estabelecimentos de ensino secundário que solicitassem o reconhecimento oficial, o inspetor federal designado deveria apresentar um minucioso relatório da verificação feita em conformidade com as normas da "ficha de classificação de estabelecimentos de ensino secundário", segundo a portaria de 15 de abril de 1932, elaborada com base nos standards de Strayer e Engelhardt.

$\mathrm{Na}$ vistoria realizada pelo inspetor, cada item foi contemplado e minuciosamente descrito. Também foram descritas as condições do contrato de aquisição do estabelecimento, destacando que estas eram muito favoráveis ao novo proprietário:

Os predios foram arrendados por cinco annos ao director do Gymnasio. Segundo o contracto, este prazo pode ser prorrogado por mais tres annos e depois, nas vezes consecutivas, por cinco annos cada vez. O contrato está legalmente feito, devidamente sellado e as firmas dos contractantes estão reconhecidas pelo $1^{\circ}$ tabelião desta cidade. As condições do contracto são muito favoráveis para o arrendatário... (RELATÓRIO de verificação apresentado ao Snr. Dr. Nóbrega da Cunha, 1935).

No relatório elaborado consta um histórico do estabelecimento; informações sobre a sua organização administrativa; lista do corpo docente com os respectivos números dos certificados de registro no Ministério da Educação e Saúde; regulamento; o regime: internato masculino, semi-internato e externato misto; e ainda os dados referentes à ficha de classificação.

A ficha de classificação era composta pelos dados relativos ao local, tais como: salubridade, ausência de ruídos, ausência de perigos ou de influências que pudessem perturbar a atenção dos alunos; dados sobre a natureza, regularidade e permeabilidade do terreno; descrição das áreas para recreio e abrigo dos alunos.

11 Foi mantida a grafia original. 
A localização das escolas assumia uma questão de grande importância, pois esta deveria estar de acordo com a missão social e educadora, evitando-se locais "antihigiênicos". A higiene se referia tanto a aspectos físicos quanto morais, portanto dever-se-ia evitar locais úmidos, sombrios e não arejados, tanto quanto a proximidade com cemitérios, hospitais, bordéis etc. ( Cf. VIÑAO-FRAGO, 1998).

De acordo com o inspetor, atendendo às exigências da Saúde Pública, a escola possuía sistema de esgoto, água encanada, rede elétrica e as ruas das imediações eram calçadas e macadamisadas.

Assim como a localização, o edifício escolar assumiu um papel importante: educar e projetar socialmente o estabelecimento de ensino. Na sequência do relatório, o inspetor passa a descrever os dois edifícios que faziam parte do colégio: um destinado às acomodações do internato e o outro para os trabalhos escolares.

$\mathrm{O}$ edifício destinado às aulas possuía dois pavimentos. No pavimento inferior, além de seis salas de aula, havia uma sala para o diretor, situada próxima à entrada principal; uma sala para a secretaria, posteriormente transformada em gabinete para o inspetor federal; uma sala para os professores; uma sala de espera para as alunas; e banheiro para os professores.

No pavimento superior, situava-se o salão nobre, destinado às conferências espirituais, literárias e científicas, concertos musicais e cinema educativo. No salão nobre eram realizadas também as aulas de música. Ainda nesse pavimento estavam localizadas as salas de Geografia; sala de História Natural; laboratórios de Física e Química; sala de desenho; biblioteca; gabinete médico; dormitórios para os vigilantes; arquivo e depósito.

FIGURA 1 - LABORATÓRIO DE FÍSICA E QUÍMICA

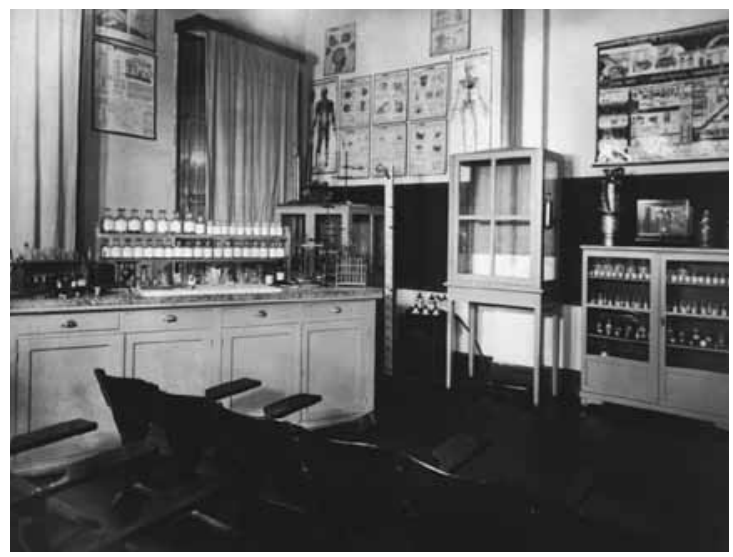

FONTE: ACERVO DO GINÁSIO BELMIRO CÉSAR (RELATÓRIO, 1935) 
Na planta do edifício das aulas observa-se a ausência de banheiros para os alunos. De acordo com as prescrições higiênicas do início do século XX, os aparelhos sanitários nunca deveriam estar no mesmo edifício das salas de aula, mas fora dele, para impedir que as exalações dos esgotos prejudicassem a salubridade das classes e das demais dependências. Em atendimento a essa recomendação, os banheiros para os alunos do Ginásio estavam localizados no pátio.

$\mathrm{O}$ inspetor relacionou todo o material didático existente nos laboratórios de Ciências, Física e Química, História Natural, Geografia e Desenho. Em cada sala de aula foram avaliadas as condições de iluminação, número de carteiras, área dos quadros, condições acústicas etc.

\section{FIGURA 2 - SALA DE DESENHO}

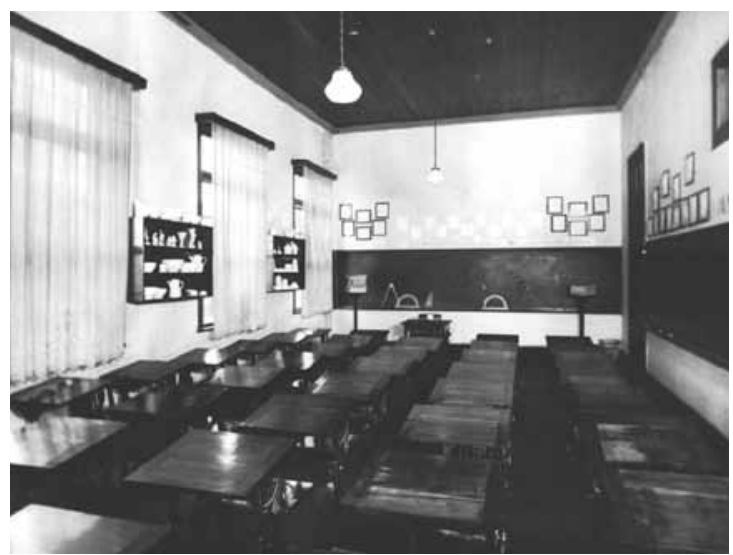

FONTE: ACERVO DO GINÁSIO BELMIRO CÉSAR (RELATÓRIO, 1935)

De acordo com o inspetor, em todas as salas de aula as carteiras foram dispostas de forma a receber iluminação sempre pela esquerda, e complementada por luz artificial. As carteiras dispostas em fila permitiam a circulação do professor entre os alunos; e o pé direito de 5 metros permitia uma boa circulação de ar.

Por fim, ao relatório foram anexadas as plantas arquitetônicas da escola, gráficos e fotografias. Na avaliação final, conclui que:

o Gymnasio Belmiro César, em conjuncto satisfaz plenamente ás condições exigidas para a Inspecção Preliminar, restando pequenos senões faceis de serem sanados e que a Directoria, aliás 
esforçada em nos auxiliar e acatar as determinações officiais, se promptificou em corrigir. (RELATÓRIO, 1935)

Em fevereiro de 1935, o mesmo inspetor, Armando Petrelli, foi designado para presidir o exame de admissão no Ginásio Belmiro César, que seria realizado em caráter condicional, ficando a sua revalidação dependente da concessão da inspeção preliminar, ainda não fornecida.

As provas escritas e orais foram realizadas nos dias 21 e 22 de fevereiro, sob a fiscalização do inspetor. Havia 37 alunos inscritos.

$\mathrm{O}$ ano letivo começaria, oficialmente, em 15 de março, porém, no dia nove de março o inspetor federal suspendeu a matrícula dos alunos que tinham feito o exame de admissão em caráter condicional, bem como daqueles que tinham solicitado a transferência para o segundo ano ginasial, pois a referida inspeção ainda não havia sido concedida.

Somente no dia 30 de março o colégio recebeu um telegrama comunicando a concessão da inspeção preliminar pelo período de dois anos.

A partir da concessão, o inspetor federal passou a visitar quase diariamente o Ginásio, e enviava um relatório mensal com todas as informações sobre o funcionamento para a Divisão do Ensino Secundário, no Rio de Janeiro. Ao final de cada ano, o inspetor fazia uma longa exposição sobre os métodos de ensino empregados no estabelecimento.

De acordo com os relatórios consultados até o momento, as considerações feitas nos relatórios eram sempre no sentido de elogiar o trabalho realizado no colégio.

\section{Considerações finais}

Para finalizar, gostaria de destacar a importância do estudo das instituições educativas para o enriquecimento da interpretação da educação brasileira em diferentes períodos da história. Acrescento, ainda, a importância do uso dos arquivos escolares, não somente em função da variedade das fontes disponíveis, mas por sua proximidade com o cotidiano e as práticas dos sujeitos que participam do fazer escolar, permitindo uma melhor compreensão da complexidade da educação escolarizada e suas práticas. $\mathrm{O}$ arquivo do Ginásio Belmiro César é exemplar dessa afirmação, pois conservou um acervo cuja fertilidade das fontes permite inúmeros estudos, tanto em função do grau de detalhamento das informações arroladas, quanto por terem sido conservadas séries documentais completas desse estabelecimento. 
Considerando que, conforme destaca Warde (2003), os estudos sobre o ensino secundário brasileiro, de caráter mais abrangente, datam dos primeiros anos da década de setenta ${ }^{12} \mathrm{e}$, além de estarem centrados no exame da legislação federal e dos dados oficiais, são marcados pelas expectativas políticas e sociais dos seus autores; considerando ainda que a maioria dos estudos disponíveis, centrados em diferentes aspectos do ensino secundário, não tem atentado para os processos de configuração dos padrões escolares e pedagógicos do ensino secundário ou, então, quando se referem aos padrões internacionais relativos ao mesmo grau de ensino, o fazem como sendo resultado da transplantação de ideias, diante da incapacidade brasileira de resolver seus problemas com alternativas locais e sem condições objetivas para colocar os padrões "estrangeiros" em prática, é patente a necessidade de reexaminar a história do ensino secundário no Brasil, sob uma nova perspectiva de análise, de maior alcance explicativo.

Acredito que incursões como a realizada por este trabalho representam um passo inicial para a constituição de novos e férteis movimentos de análise.

\section{REFERÊNCIAS}

ABREU, Geysa Spitz Alcoforado de. Escola Americana de Curitiba (18921934): um estudo do americanismo na cultura escolar. Dissertação (Mestrado) - PUC/SP. São Paulo, 2003.

ALVES, Claudia Maria Costa. Estado conservador e educação no Brasil: o caso do Liceu Provincial de Niterói (1847-1851). In: NUNES, Clarice. O passado sempre presente. São Paulo: Editora Cortez, 1992.

BRASIL. Decreto n. 16.782-A, de 13 de janeiro de 1925. Collecção das Leis da República dos Estados Unidos do Brasil de 1925. Rio de Janeiro: Imprensa Nacional, 1926.

BRASIL. Decreto n. 19.890, de 18 de abril de 1931. Dispõe sobre a organização do Ensino Secundário.

BRASIL. Decreto n. 21.241, de 4 de abril de 1932. Consolida as disposições sobre a organização do Ensino secundário e dá outras providências.

12 Tais como: Gouveia e Havighurst (1969), Dodsworth (1968), Haidar (1972), Marques Jr. (1967), Nunes (1962), Peres (1973), Silva (1959, 1969). (apud WARDE, 2003). 
HAIDAR, Maria de Lourdes Mariotto. O Ensino Secundário no Império Brasileiro. São Paulo: Edusp, 1972.

JULIA, Dominique. A cultura escolar como objeto histórico. Revista Brasileira de História da Educação. Tradução: Gizele de Souza. São Paulo: Autores Associados, n. 1, p. 9-43, jan./jun. 2001.

NUNES, Clarice. Escola \& Dependência: o ensino secundário e a manutenção da ordem. Rio de Janeiro: Achiamé, 1980.

. O "velho" e "bom" ensino secundário: momentos decisivos. Revista Brasileira de Educação, n. 14, maio/jun./jul./ago. 2000.

STRAYER, George D.; ENGELHARDT, N. L. Standards for Elementary School buildings. Bureau of Publications. New York: Teacher's College, Columbia University, 1933.

VIÑAO FRAGO, Antônio; ESCOLANO, Augustin. Currículo, espaço e subjetividade: a arquitetura como programa. Tradução: Alfredo Veiga Neto. Rio de Janeiro: DP\&A, 1998.

WARDE, Mirian Jorge. Americanismo e Educação: a fabricação do "homem novo". Projeto de pesquisa desenvolvido no Programa EHPS, com apoio da Capes e do CNPq, 2001.

. Internacionalização-Nacionalização de padrões pedagógicos e escolares do ensino secundário e profissional (Brasil, meados do século XIX ao pré-Segunda Guerra Mundial). Projeto de pesquisa desenvolvido no Programa EHPS, com apoio do CNPq, 2003.

Fontes Primárias do acervo do Ginásio Belmiro César

BRASIL. Ministério da Educação e Saúde. Classificação dos Estabelecimentos de Ensino Secundário. Curitiba: Acervo do Ginásio Belmiro César, [193?]

RELATÓRIO de verificação apresentado ao Snr. Dr. Nóbrega da Cunha, D.D. Inspector Geral do Ensino Secundário, para fins de concessão de Inspecção Preliminar, realizado pelo Inspetor Federal sr Armando Petrelli, do Collegio Iguassú, 1935. Fotografias diversas.

Texto recebido em 18 de maio de 2009.

Texto aprovado em 24 de junho de 2009. 